\title{
CHILD PROTECTION OF CHILDREN ON THE MOVE - SERBIAN CONTEXT
}

\section{Iva Branković ${ }^{1}$ \\ Anita Burgund Isakov}

Republic Institute for Social Protection

Faculty of Political Sciences University of Belgrade

\section{Scientific review paper}

\begin{abstract}
This paper presents findings of a research about the systematic solutions to the needs of migrant/ refugee children, who were passing through Serbia during the transit period in 2015 and 2016. The aim of the research is to analyze systematic solutions to the needs of the children and to define recommendations for improving the protection of unaccompanied children during the migrant crisis.

It involved 17 professionals from Centers for Social Work and 18 representatives of governmental and non-governmental sector, who shared their experiences by participating in the individual interviews and focus groups. One of the key findings identified is the need to establish mechanisms for enhancing cooperation among stakeholders in relevant systems, especially between the social protection system and the non-governmental organizations at the local level. Furthermore, a special part of the research is dedicated to official child protection procedures in cases of unaccompanied children and children at risk as it was noticed during the research preparation that, in addition to the uncertainty with respect to roles and difficulties in communication among various actors, there is a particularly significant challenge in the child protection system considering the doubts about the steps in the process of protection of children migrants/refugees in the specific circumstances of their passage or prolonged stay in Serbia.

Key words: migrants / unaccompanied refugee children, child protection, systematic solutions to the needs of the protection of children migrants/refugees, child protection procedures, Center for Social Work, case management

\section{INTRODUCTION}

In 2015, Europe was affected by an immense migrant/ refugee crisis, counting over one million of refugees/ migrants from various areas affected by wars and conflicts. Although Serbia is dominantly a country

of transit, in which migrants/refugees usually remain only for a short period of time (in 2015, the average retention period was only a couple of days), migratory tendencies in 2015 and in early 2016 unambiguously indicated an increase in the number of migrants/ refugees.
\end{abstract}

\footnotetext{
Correspodence to:

Iva Branković, Republic Institute for Social Protection, Belgrade, Serbia

E-mail: brankoviciva@yahoo.com
} 
The circumstances under which migrations take place have a remarkable impact on the safety and wellbeing of the child. The sudden commencement of an emergency, war, violence and family breakdown significantly affect the physical and psychological wellbeing of refugee/migrant children (Child Protection Working Group, 2012). Therefore, migrations demand urgent reactions because they cause extreme health and social risks for the child's growth and development, as well as for the family functioning. In accordance with the internationally accepted refugee/migrant protection standards and respecting, to the extent possible, their specific needs and interests, the Republic of Serbia provides children and their families with the protection and support through the application of relevant laws and social protection measures.

More than 600,000 refugees and migrants have traveled through Serbia, and it has been estimated that children represent $25-30 \%$ of this population (according to the estimates of the Commissariat for Refugees and Migration (2016), there have been approximately 150,000 children). At the end of March 2016, about 2,000 migrants/refugees and asylum seekers were present in Serbia, of which 1,703 were in the governmental accommodation units around Belgrade, Preševo and Šid (UNHCR, 2016). During the research realization period (June 2016), there were still talks about 2,000 migrants living in Serbia, mostly families, women and children who were illegally traveling through Serbia, hoping that they would still be able to cross the border with Hungary and come to the European Union. The specificity of this outbreak covered by the research is the increased number of underage immigrants and the increased risk of smuggling and trafficking in human beings, which is a particularly important warning signal for all systems, especially system of social protection.

Children constitute a delicate part of the migrant population that becomes seriously endangered in cases of children who are separated from their parents/guardians, as well as unaccompanied children (ENOC Taskforce Children on the move, 2016). According to the data from the Ministry of Labor, Employment, Veterans and Social Affairs "in the last year about 230 underage migrants without responsible adults to accompany them were registered in Serbia" (RTS, 2016). Centers for Social Work in Serbia are responsible for assessing the risk and vulnerability of children and young people, for following the procedural and methodological steps in the cooperation with other organizations from the state and non-governmental sector in order to protect the most vulnerable children and, if necessary, to provide immediate intervention. The retention of migrant/refugee children has also caused the need for an adequate, permanent care of children, for which institutions, such as asylum centers and accommodation facilities from the social protection system (foster care centers, childcare facilities, reception units of the institutions for education), are responsible. In addition to the housing facilities, the non-governmental sector represents a significant resource in times of crisis since their services are aimed at providing immediate support to migrants/refugees in fulfilling their basic needs. Moreover, there are international organizations that provide resources, coordination, training and support both at national and at the local level.

The research, "Protection of Child migrants - experiences and recommendations," was prompted by the fact that during the migration crisis there were many actors in the field who provided support to or were in some way responsible for the migrant/ refugee children, leading to various disagreements and barriers in finding ways to provide effective support as a result of the lack of experience. Given that the countries in the region have experienced similar challenges, the aim of the research is to understand the factors that lead to problems, as well as to create recommendations for overcoming them and improving the mechanisms for the adequate response of the system to the complex needs of child migrants/refugees.

\section{Instruments for the protection of child migrants/ refugees}

The issue of unaccompanied and separated children poses a complex problem requiring government agencies to find new ways of working together in innovative constellations and with new partners as well to operationalize the principles of relevant international instruments as well as national regulations. The most recognized international instrument for the protection of children in emergencies is the Convention on the Rights of the Child, which defines the protection of children as a key legal instrument. 
Furthermore, many international documents related to the protection of children in the emergency situations are based on The Convention on the Rights of the Child (UNICEF \& UNHCR, 2014), as well as the procedures for the protection of the children within the system of child social protection in the Republic of Serbia. The four key principles of the Convention related to the protection of child migrants/refugees are: The Right to protection of the best interest (Article 3), The Right to non-discrimination (Article 2), The Right to life, survival and development (Article 6), The Right to Participation (Article 12). Applying these principles when protecting children on the move means that the best interests of the child should be essential in making the decisions and in the implementation of activities involving children. Assistants working with children are expected to provide help regardless of the sex, age, disability, social class, ethnicity, religion, language, political conviction or sexual orientation. Moreover, they are obliged at all times to show respect for all differences that a child might possess. All actors involved in providing support to children on the move have a responsibility to provide to children all requirements neccesary for their development. Securing the right to participation is of a particular importance for children on move, as they are encountered with the need to make numerous decisions that significantly affect their lives. In addition to these four principles, the Convention on the Rights of the Child prescribes other basic rights, such as, inter alia, the need to be protected against all forms of violence, exploitation and neglect, as well as the right to the physical and intellectual development of a child. The Convention underlines the importance of family in children's lives, but also devotes special attention to the needs of children without parental care and asylum seekers or refugee/migrant children (UN Convention on the Rights of the Child, 1990).

Relevant national regulations for the protection of children refugees/migrants are based on the following laws, regulations and protocols of the Republic of Serbia: Family law: regulates custody of the child, parental rights and the child's administrative capacity (Family Law, 2005); The Law on the Social Protection: defines the basic regulations for ensuring the child care in the social protection system (The Law on Social Protection, 2011); Rulebook on the organization of the Center for Social Work: defines the basic professional procedures and manners of exercising the public authority of the Center for
Social Work as a guardianship implementation body (Rulebook on organization, norms and standards of work of the Center for Social Work, 2012); General and special protocols for the protection of children against abuse and neglect: cite criteria for differentiating child abuse and neglect and clearly link the institutions of the system to the protection of abused and neglected children (Milanović, Perišić i Milić, 2016). Finaly, in order to enable the equal engagement of all social welfare institutions in providing assistance and support to refugees, the Ministry of Labor, Employment, Veteran and Social Affaires has issued an Instruction about the conduct of Centers for Social Work and Social Protection Residential Institutions in providing protection and accommodation of unaccompanied minors (MoLEVSA, 2015) as well as the Action Plan for providing protection and accommodation of the unaccompanied underage migrants.

\section{RESEARCH METHOD}

For the purpose of the research, qualitative methodology of interviews and focus groups has been used. Focus groups allow observing the ways in which respondents engage in planning, and how they understand their participation, as well as the concerns, expectations, fears and challenges, together with the sources of support that are available to them during the migration crisis processes. Moreover, focus groups are based on dialogue and action dynamics, thus, they enable describing the phenomenon and understanding its quality through a dialogue (Đurić, 2005).

The research includes a sample of 17 professional workers from the Centers for Social Work and 18 representatives of the governmental and non-governmental sector that participated in individual interviews and focus groups in order to share their experiences. Interviews with employees from $6 \mathrm{CSW}$ who had experience in working with migrants during the migrant crisis represent the basis of the research. Interviews were conducted with managers, supervisors, case managers, field workers engaged in the migration crisis and their coordinators ${ }^{2}$.

\footnotetext{
${ }^{2}$ All interviews have been transcribed and encrypted so each respondent received the code: R-respondent, gender ( $\mathrm{m}$ or $\mathrm{f}$ ), a letter that indicates his/her position in the Center for Social Work (f-field worker, CS-case manager and C-coordinator ), and the number that the respondent has.
} 
Furthermore, three focus groups were completed with representatives of governmental, non-governmental and international organizations, as well as with representatives of institutions for the accommodation of children during the migration crisis, which included 18 associates, 13 women and 5 men $^{3}$.

Data from focus groups was processed qualitatively, by the means of a thematic analysis. The thematic analysis took place at two levels: semantic and latent. Semantic analysis was concerned with the categorization of topics on the basis of the explicit content that respondents reported, while latent content refers to the meanings related to the interpretation of responses provided by both respondents and researchers (Žižak et al., 2012). Qualitative analysis of the focus groups included the following phases: reading the complete focus group transcripts, determining the coding unit, defining codes for each participant, creating categories at the sub-sample level, interpreting the results obtained for each sub-sample of participants together with supporting the categories with the literal quotes of the focus group participants.

\section{RESULTS AND DISCUSSION}

The results of the research are presented in several thematic parts, following the structure of the interviews and focus groups, but also in line with subthemes identified during data analysis which are described and illustrated by the corresponding quotations. Thematic parts are presented as following: cooperation among relevant actors, challenges encountered in protecting child migrants/refugees, resources to meet the needs of child migrants/refugees, child protection procedures during the migrant crisis, with the focus on the Center for Social Work since it is an institution accountable for identification and protection of vulnerable children migrants/refugees and children at risk, characteristics of case management in specific circumstances of migrant crisis, overall capacities of the Center for Social Work to respond to the needs of child migrants/refugees and the quality of the normative framework concerning regulations and guidelines governing the response of the social protection system and the cooperation among different actors in the protection of child migrants/refugees.

\footnotetext{
${ }^{3}$ The results have also been encrypted through a code for respondent, gender, and a number, like in the interviews, but with the FG index in order to create a difference with respect to the material obtained through the interviews.
}

\section{Cooperation among relevant actors}

The research has covered issues about the number and understanding of the migratory movements at the territory of Serbia, with all actors giving different estimations (from seven to 200-300 migrants) relative to the region they come from. Different estimations are understandable considering that the survey was carried out in the period of evident changes due to the longer retention of migrants/refugees and reduced legal flows of people. Registration of unaccompanied children is further hampered by the difficulty of determining the age of children and illegal smuggling after the closing of the Balkan route. IFG1: Documentation of cases was lacking (...) Those who were not identified as the most urgent were not documented, there were many failures.

Participants in the research have identified a large number of actors working in the field with migrants and showed clear understanding of their activities, responsibilities and inherence within the protection of child migrants. The cooperation between the governmental and the civil sector has been described as good, positive and improved with respect to the beginning of the refugee crisis. Representatives of the state and international institutions emphasized the importance of cooperation between the state and the civil sector in situations such as migrant crisis that exceeds the capacity of the state to respond to the needs of protection, thus the existence of the civil sector is significant. However, at the beginning of the migration crisis, there were numerous challenges in cooperation due to the communication problems among different actors, as well as the lack of understanding of roles between different actors as well as boundaries between their responsibilities and inherence. Representatives of all sectors have disclosed cases where representatives of non-governmental organizations took over the role of the Center for Social Work (CSW) in determining the vulnerability of the child, assessed and made decisions which are out of their jurisdiction; as well as the cases in which they expressed dissatisfaction with the way in which CSW determined the level of risk. IWVS1: It sometimes happens that those NGO stakeholders are not satisfied with our assessment. (...) It often happens that those calls are completely unnecessary (...) they say that they have an unaccompanied minor. When we arrive to the field, it turns out that somewhere around there is his/her father, mother, uncle ... so there was no need to call us at all. 
Considering the cooperation with governmental institutions, primarily with the Centers for Social Work, representatives of the non-governmental sector also note that there has been a great progress compared to the beginning when they had the impression that representatives of the state did not listen to them and that there was a huge gap between them. Additionally, they openly raise doubts about the accuracy of some Center for Social Work' decisions, because they believe that the social protection system included new people (field workers) in the process of protection without necessary preparation, in order to respond to the needs of migrants as fast as possible. However, those people usually have neither experience, nor the necessary knowledge and skills. IFGM1: The system is generally messed up in a way that many inexperienced people have been put in to deal with refugees, and refugees are a very serious thing. Those people often have a good will to help but they lack experience.

\section{Challenges in the protection of child migrants/refu- gees}

Regardless of the period of the migration crisis, all participants have agreed that one of the greatest difficulties in protecting the child migrants is the challenge of identifying the age of child migrants/ refugees. Children and young people often do not communicate their age for various reasons and they don't have any documents. Since no method for determination of someone's age is currently available the identification of the age is limited to accepting their testimonies. There are suggestions for introducing some methods, such as training for determining the age by bone development and size, but for now they are not being used. IFG5: The problem in assessing the age occurs when children are between 15 and 18 years old, methods for determining age are expensive and that is an obstacle.

The problem of smuggling is recognized as a major challenge in assessing the vulnerability of children. As all children are accompanied by an adult, it is very difficult to distinguish a responsible adult from a smuggler. Furthermore, it is difficult to determine whether the adults they travel with are really their relatives, as well as whether they have the capacity to take care of those children. IFGM4: We had many groups of children that consisted of one 17-year old and for example 5 or 6 boys who were around 8 or
9 years old. I think that the focus should be on the leader of the group ... Whether he can take care of them and what is his interest.

All representatives of the governmental sector stressed problems that arose due to the lack of an interpreter. They emphasized that child refugees have the same treatment as children without parental care only on paper. In situations without an interpreter, who would enable the understanding of a language, culture and civilization context from which they come from, these children are provided only with elementary needs: basic security, food, clothes and "roof over the head". IFGM1: "It's not real, we have no interpreter, we cannot provide the same treatment." Representatives of the Centers for Social Work claim that not understanding the language in assessing the vulnerability of a child creates many problems. At the practical level, it slows down the process at the moment the child is identified. On the other side it affects the quality of care because the language barrier interferes with creating rapport with the child and therefore presents an obstacle for adequate assessment of the situation and needs. The lack of translators imposed another barrier to better protection of the children that came from the inability of the same translator to "follow" the entire procedure related to one child. IFGM3: When a child is placed somewhere, the first contact he has is with an interpreter, and then he loses that contact. Children, especially younger, ask us: "Will I see you tomorrow?".

\section{Resources for meeting the needs of child migrants/ refugees}

Representatives of the Centers for Social Work state that the systemic response to the essential need of children at risk, a need for accommodation, has been largely answered for the time being, although the accommodation units of the social protection system have occasionally been unable to respond adequately. The main difficulty in the work of accommodation providers lies in the lack of a clearer procedure and alternative accommodation in cases of children staying longer than planned. The services of the reception centers and accommodation facilities are intended for the transit period and provide basic needs in the form of food, clothing and information, while longer child retention requires the provision of structured activities in accordance with their development developmental needs. 
An additional problem is the situation, in which children neither have the possibility to legally cross borders, nor they desire to seek asylum in Serbia. These children are in a state of waiting and uncertainty, which is another difficulty for both them and the professionals who cannot plan for long-term nor can they apply a structured approach. Izkk1: There are no structured activities. There are, for example, those non-governmental organizations' mobile teams; there is this corner for children, but...

Only one Center for Social Work has developed the practice of placing children in foster families during the migration crisis, and this is stated as a very positive experience. All respondents agree that family accommodation is a resource that needs to be further empowered, through mobilizing and motivating foster families, so they can meet the specific needs of younger child migrants/refugees.

Moreover, all focus group participants agreed on the importance of ensuring the availability of education for all children, and even for children in the migration process, but with the remark that this issue should be approached with caution. The participation of the education system in this context has been recognized as necessary, through the creation of programs tailored to child migrants and the creation of non-formal education, as well as the sensitization of the local community. IFGM1: Never send children to school without serious preparation because it is a source of traumatization.

\section{Child protection procedures during the migrant cri- sis - the role of the center for social work}

In accordance with their competencies Centers for Social Work are engaged in situations when, upon the notice from the police or non-governmental organization, they discover that there is a minor at risk or unaccompanied (Rulebook on organization, norms and standards of work of the Center for Social Work, 2012). The representative of the Center for Social Work (case manager or field worker that is specially employed during the migration crisis ${ }^{4}$ ) comes to the field and, together with the minor, goes to the police for registration.

\footnotetext{
${ }^{4}$ The specific characteristic of the work of field workers is that they have a limited mandate, that is, they can assess the risk and make a decision that the child should be urgently separated from the group in which he is located and arrange for accommodation, but they cannot be guardians, which is an option only for professional workers of the Center- case managers
}

An assessment of the degree of vulnerability is carried out, and if it is established that the minor is at risk or without accompanying responsible adult, the Center appoints the guardian. IMVS9: The police inform us about everything. We have a mandatory 24hour on call duty. From the first moment when it is registered that a child is unaccompanied, his temporary guardian is appointed (orally).

In a methodological sense, the procedure for identifying children at risk by the CSW involves steps similar to those when working with a regular population in situations of immediate interventions. First, an assessment of the condition of the child is carried out and the urgent needs related to safety, nutrition, personal hygiene and clothing are met. At the same time, information is gathered about the child, what is his/her age, when did he/she come to Serbia and who he/she is traveling with, where are the parents and whether there are any trustworthy adults around. The risk assessment can lead to the conclusion that the child is not endangered and that he/she can continue his/her stay or the journey with the group he/she is with, then the Center for Social Work stops the procedure. The other conclusion may be that the child is at risk, that he needs to be relocated and taken care of, in which case the accommodation for the minor is being organized in one of the institutions for that purpose.

The key dilemma for the representatives of the Center for Social Work in determining the best interests of the child is whether to separate the child from the group he/she is traveling/staying with or not, especially in situations where in that group there are no parents or close relatives of the child. Experiences in resolving this issue are different and vary on a caseby-case basis, mostly depending on the available information about the child and about members of the group he/she is traveling with. However, among the representatives of Centers the belief predominantly represented is that the child should not be separated from the group she/he travels with, even if there are no relatives or close people in the group, mostly because it is considered much safer for a child to be in the group with the people he/she knows. IMVS9: Most of these migrants are from a totally different cultural environment (...) For example, we think that the Syrian child is travelling alone, while he is travelling with the tribal head of the village, who, in our point of view, is not related to him, whereas according to their tradition he is more important to the child than the uncle or any other relative. 
Other big dilemma is related to those situations in which children clearly express the desire to continue the journey, despite the opinion of the professionals that that is not in the child's best interests. IFGm4: There are many minors around 12 years old, who are overly concerned with the idea that they need to arrive somewhere and earn some money". Participants agreed that in those situations, it is important to enable the children to continue their journey legally and to arrive to the destination where their needs will be met in accordance with their age. IFG6: The boy who was with us went to Sweden legally with an idea to work there. He is now in the boarding school and he does not work, but the only way to save those kids is to enable them to legally go somewhere and to be accepted there with legal documents.

\section{Characteristics of case management during the migrant crisis}

Considering the case management, the representatives of Centers for Social Work have had different opinions, but in their statements, regardless of their position in the Center, there is a common understanding that a key obstacle to the realization of the case management is the short retention of migrants and children in Serbia. They consider the regular procedure, involving implementation of all phases of the case management (Žegarac, 2015) in the context of migrants passing through Serbia too complicated and useless, since it prescribes a lot of steps in a situation on a field that, however, requires fast decision-making and urgent reactions. The situation after the closure of the Balkan route, when a part of the refugees/migrants remained in Serbia, opened more room for, as said by one of the interviewees" a more serious level of work". IMVS5: Experience and case management are determined by the nature of their stay in Serbia which is transitory. There are, also, those children who are stuck here for some specific reason. Again, the case is being raised to a more serious level due to the length of the stay and the type of services that need to be provided. Respondents were trying to apply the principles of case management (Child Protection Working Group, 2014), but this attempt was hampered by the lack of data, language barriers, "the abduction of children from their natural context" and the like. It is important to point out that on the questions on terminology and the principles of the case management the majority of professionals did not respond to or answered in and unclear and undetermined way. The impression is that a large part of the migrant protection practice was based on the current improvisation and the search for alternatives in a completely new situation for which there was no preparation, and there was certainly no specific experience from the past that could be applied.

\section{Capacity of Centres for Social Work to respond to migrant crisis}

All Centers for Social Work that participated in the research had on-call duty organized 24 hours a day. Furthermore, Centers that have employed field workers were satisfied with the work organization, stating that without the support of field workers they would not be able to provide that level of availability of professional workers on the field. On the other hand, in Centers that did not have hired field workers, the 24 hours responsiveness has often caused fatigue within the workforce, and sometimes even difficulties performing regular tasks. IMS11: It is difficult to organize work when two workers are on on-call duty for a month. Often during the night, one takes care of the accommodation and then in the morning he/she comes to work. Besides the problem regarding human resources, majority of Centers in transit areas also had difficulties in organizing transportation due to the lack of vehicles, but also other material and technical conditions. IMS6: We, as a Center, do not have the resources (...) unless we have additional financial or project support. Unless we have someone to finance it, we cannot support 24 hours duty.

All representatives of the Centers report about the case overload and stress to which they have been continuously exposed, as well as about very high expectations of other systems and stakeholders, and in some situations, the feeling of powerlessness and emotional fatigue. Nevertheless, during the migration crisis, no Center paid special attention to the need for the adaptation of supervision to the extraordinary circumstances. IMT4: Working on the field is exhausting, stressful and very unpredictable. There should be some activities aimed at preventing burnout syndrome, more inter-organizational sessions for exchanging the experience and capacity building for the further work, as well as more individual supervisions. 
Normative framework - advantages and disadvantages

All participants in the research have identified a large number of regulations that were useful to them while working with unaccompanied refugee children in the area of social protection and family law, as well as asylum and migrations management law. They also asserted that in all areas it is necessary to revise regulations based on experience from the previous period in order to make them more adequately correspond to the reality. IFgm4: Our Asylum Law was written in 2008 when there were dozens of migrants. The complexity of the matter, and its changing nature, is shown by the fact that the State still cannot pass the new Asylum Law.

In addition to the regulations that specifically regulate the work of their institutions, all actors were familiar with the Instruction on the conduct of the Center for Social Work and of Social Protection Institutions for accommodation of beneficiaries in providing protection and accommodation for unaccompanied minors (Instruction). Moreover, CSW representatives indicated that the Instruction provides a good enough framework for action and serves as a guideline due to the lack of specific internal procedures for working with migrant children. Some of them agree with their colleagues working on accommodation services, that there is a room for improvement of this document, especially with respect to the alternative ways of accommodating children and using foster care as a resource for taking care of the children. In relation to the institute of a temporary guardian, representatives of NGOs have pointed out the disadvantages of current practice based on the procedure that in each new environment a child is placed in a new temporary guardian is appointed for him/her, whereas after the child is transferred from one municipality to another they no longer have any form of communication. Furthermore, some CSW representatives have pointed out to a systemic problem stemming from the fact that the appointed guardian for a child needs to be a citizen of the Republic of Serbia and they believe that the procedure would be significantly facilitated if the appointed guardian could be one of the people travelling with a child, and who may not even be a direct relative but can better decide on the interests of the child than the CSW representative. IMK3: The disadvantage is that the guardian traveling with the child, a person considered trustworthy by child's parents, has reduced power in Serbia and that creates a problem. He can, for example, take care of the child, of his important needs, health, safety, and so on, but he cannot represent him when he is out of his country. Representatives of the accommodation services pointed out to the another systematic disadvantage, which refers to the absence of services that depend on the status of the child. Namely, children who have the status of asylum seekers have the same rights as citizens of the Republic of Serbia and they have all the services of health, social and other protection available, which is not the case with child migrants. IFG 7: What we did not manage is to overcome the difference between the child migrant and the asylum seeking child. We take children to see the doctor but she cannot write a prescription. She writes on the paper and then we call NGOs to provide us with the medicine.

As an opportunity to overcome the barrier between responsibilities and competencies of state and nongovernmental organizations, representatives of state organizations have acknowledged the newly drafted Standard Operational Procedures (SOPs), which regulate the competencies of all involved actors. On the other hand, representatives of the NGO sector expressed their concerns regarding this document, noting that due to its complexity, a thorough training of field workers for its preparation is necessary.

Despite stating that the cooperation among all relevant actors in responding to the crises has become very good, all respondents believe that it would be necessary to institutionalize this cooperation, that is, to make general instructions, based on this experience, for working under extraordinary circumstances that will be binding on all, and not just for the social protection system. IMVS8: The only thing missing is the exact identification of a procedure that will oblige all participants and show them how to behave.

\section{CONCLUSION AND RECOMMENDATIONS}

Research results show that the protection system responded in a timely manner including many relevant stakeholders in the process, but since there was no previous experience various obstacles and barriers were encountered. All participants report on lack of coordination in the field and difficulties in achieving mutual understanding during risk assessment between sectors, lack of material and technical resources in the government sector and need for improvement of skills for working with migrant children and information sharing among all relevant stakeholders. 
Having this in mind the main recommendation for improving the response system to the challenges of the migrant crisis is related to the enhancement of cooperation among the relative stakeholders. This area could be improved by the strategic planning of the country's response to the migrant flows, including activities regarding the integration of migrants to whom Serbia is the final destination. The strategic plan should define the right path for establishing a regional communication network and for improving communication and coordination among different actors in Serbia, but also for regulating the normative framework. The new normative framework should enable identifying a systematic solution for the improvement and adjustment of the role of a temporary guardian, determined for unaccompanied migrant children, as well as for ensuring the access to services to all children, both minors and asylum seekers in the same manner. Thus, it is necessary to create and adopt the universal instruction that will be binding on representatives of all relevant systems (social protection, police, health, education ...), and whose part could include the standard operating procedures for the social protection system and all other crucial actors. Moreover, the development of improved guidelines for the cooperation among all relevant actors would support the practitioners and enable greater availability of services dedicated to migrants through the creation of the list of contacts of both professionals and service providers with clearly defined areas of expertise and support options.

Another important area is the improvement of the child protection system for children migrants/refugees, through the following activities: introduction of the modern methodology for age determination and through the education of professionals assessing the vulnerability of the child for its implementation; improving the assessment of child's vulnerability by focusing more attention on the ability of the group leader, with whom the child is currently living/traveling, to take care of the child; organizing trainings for members of all sectors who have direct contact with a minor for age and developmental needs appropriate interviewing; improving the process of documenting cases with a special focus on migrant children. In response to the need for long-term accommodation, it is necessary to improve the normative framework of conduct in order for it to provide clear directions of financing and define effective procedures. For the accommodation of small children, it is necessary to facilitate resources in the form of foster families and for older children to create alternative accommodation options.

Furthermore, in order to ensure the strengthening of capacities of all actors on the field, it is necessary, above all, to enhance CSW both materially and technically with greater access to resources for financing services provided to migrants. For the purpose of more efficient organization of work, centers and institutions for social protection should be supported in the creation of internal procedures for emergency response and for the formation of special teams with the engagement of field workers, who would be only working on the protection of child migrants and therefore, possess relevant qualifications and skills. Empowering Centers' employees should be

based on providing information and education for the development of culturally competent practice, and in particular for the development of skills needed to conduct interviews with migrant children via an interpreter. Advancement of competencies is needed for provision of tailored supervisory support to the staff engaged in direct work with migrants in order to prevent professional burnout. Additionally, all actors on the field need to have access to trainings for enhancement of skills necessary for provision of psychological first aid, as well as with a continuous education for determining the vulnerability and best interest of the child.

In order to activate resources and utilize the potential of the community, it is necessary to prepare and inform the local population in environments where children are expected to stay longer, as to facilitate better integration of children into the local community. Moreover, it is necessary to create services for the preservation of migrant/refugee families in the community that would be available to them while they are on the territory of Serbia and to engage the resources of the non-governmental sector in creating and providing services on the field where the child migrants/refugees are located in order to enable them as much structure and development as possible during the migratory movement. It is also important to create conditions for meeting the educational needs of child migrants/refugees in a way that is appropriate to their specific situation and context.

Finally, in order to improve direct work with children and raise the quality of services provided, systematic planning of child protection in needed, taking into account the need for continuity in working with the child and avoiding exposure of a child to a large number of professionals who will assess and provide care. 
In addition, accommodation services providers should be educated on the ways of communication, cultural and other specificities, and all activities with children should be planned in respect of cultural differences, especially the gender issues with the emphasis on the specific needs of girls from the migrant population.

\section{REFERENCES}

Child Protection Working Group CPWG (2014). Inter Agency Guidelines for Case management and Child Protection.

Child Protection Working Group CPWG (2012) Minimum standards for child protection in humanitarian action. Internet: http://cpwg.net/?get=006914\%7C2014/03/CPMinimum-Standards-English-2013.pdf 20/08/2017

Commissariat for Refugees and Migration of the Republic of Serbia, Internet: http://www.kirs.gov.rs/articles/navigate. php?type1=3\&lang=SER\&id=2325\&date $=0$ 20/08/2017

Convention on the Rights of the Child. Official Gazzete of SFRJInternational contracts and other agreements, No.15/90 and Official Gazzete SRJ - International contracts and other agreements, No.4/96 and 2/97

Family Law, Official Gazette of RS, number 18/2005, 72/2011and other law and 6/2015

Law on Social Protection, Official Gazette of RS, number $24 / 2011$

Rulebook on organization, norms and standards of work of the Center for Social Work, Official Gazette of the RS, no. 59/2008, 37/2010, 39/2011 - other rulebook and 1/2012 other rule book
Radio Television of Serba RTS (2016) Internet: http://www. rts.rs/page/stories/ci/story/124/drustvo/2311900/evidentirano-230-maloletnih-migranata-bez-pratnje.html 10/08/2017

Milanović, L., Perišić M., Milić, M. (2016). Standardne operativne procedure - zaštita dece izbeglica/migranata. IDEAS, Beograd.

Ministry of Labour Employment Social and Veteran Affairs MoLESVA(2015) Instruction on the conduct of the Center for Social Work and of social protection residential institutions in providing protection and accommodation for unaccompanied minors.

ENOC Taskforce Children on the move. (2016). Safety and Fundamental Rights at stake for Chidlren on the Move. Internet: https://www.dekinderombudsman.nl/ul/cms/ fck-uploaded/2016KOM.00\%20Safetyandfundamentalrightsatstakeforchildrenonthemove.pdf 13/08/2017

UNICEF\&UNHCR (2014) Safe and Sound: What states can do to ensure respect for the best interest of unaccompanied and separated children in Europe.

UNHCR Serbia Daily Update 21 March 2016.

Đurić, S. (2005). Metodologija fokusgrupnog istraživanja. Fakultet civilne odbrane, Beograd. http:/www.doiserbia.nb.rs/img/doi/0038-0318/2005/0038-03180501001D. pdf, 18/05/2017.

Žižak, A., Koller-Trbović, N., Jeđud Borić, I., Maurović, I., Mirosavljević, A., Ratkajec Gašević, G. (2012). Udomiteljstvo djece iz dječje perspective. Kriminologija i socijalna integracija, UNICEF, 20, 1, 1- 132.

Žegarac N. (2015). Od problema do prilika u vođenju slučajaPriručnik za praktičare, UNDP, Crna Gora. 